\title{
Community mental healthcare in Lebanon
}

\author{
Амбулаторная психиатрическая служба в Ливане \\ DOI: 10.17650/2712-7672-2020-1-1-71-77
}

\author{
Joseph El-Khoury, Riwa Haidar, Raghid Charara \\ Department of Psychiatry, American University of Beirut \\ Medical Center
}

\author{
Джозеф Эль-Хури, Рива Хайдар, \\ Раджид Чарара \\ Кафедра психиатрии, Медицинский чентр \\ Американского университета Бейрута.
}

\begin{abstract}
Lebanon is a medium-income country in the Eastern Mediterranean which has seen a surge in interest in mental health over the past two decades following years of stagnation. The mental health needs of the country at primary care level and for severe psychiatric disorders are underserved. Political instability, chronic underfunding and widespread stigma have all contributed to maintaining a traditional model of private clinics affiliated with inpatient and long-stay psychiatric units. A number of initiatives have recently been launched to cater for patients with psychotic disorders and also to offer partial hospitalization for others with mood-related conditions. In parallel, the Ministry of Public Health, with international funding, has been instrumental in its efforts to standardize care at a national level, particularly for early detection and treatment in primary care settings. The priorities of the national mental health programme are consistent with the global trend in shifting services to the community. Hurdles remain, in line with those facing countries with similar socio-demographics and resources. These include limited third-party coverage of mental health, absence of training opportunities in multidisciplinary community settings and some clinicians' reluctance to update their ways of working. Development of a local workforce, familiar with evidence-based models of care and dedicated to providing a patient-centred approach in the least restrictive settings, is essential for consolidating community care in Lebanon. This would be reinforced by (overdue) legislation and implementation of a mental health law.
\end{abstract}

\begin{abstract}
АННОтАЦИя
Ливан - страна со средним уровнем доходов, расположенная в восточной части Средизем-номорья. В последние 20 лет, после долгого периода стагнации, в Ливане наблюдается рост интереса к вопросам психического здоровья. Потребности страны в психиатрической помо-щи на уровне первичного звена здравоохранения, а также при лечении тяжелых психических расстройств удовлетворяются недостаточно. Политическая нестабильность, хроническое недофинансирование, повсеместная стигматизация больных - все эти факторы вносят вклад в поддержание традиционной модели, когда частные клиники существуют при психиатриче-ских стационарах и стационарах длительного пребывания пациентов. Недавно в стране нача-лась реализация ряда инициатив, нацеленных на помощь пациентам с психотическими рас-стройствами, а также на обеспечение частичной госпитализации пациентов с аффективными расстройствами. Параллельно с этим Министерство здравоохранения страны, опираясь на международное финансирование, успешно реализует программу стандартизации психиатри-ческой и психологической помощи на национальном уровне, уделяя особое внимание мерам по раннему выявлению расстройств и лечению в системе первичной медицинской помощи. Приоритеты национальной программы по охране психического здоровья согласуются с об-щемировой тенденцией приближения помощи к месту жительства пациента. Тем не менее, как и в странах со сходными социально-демографическими характеристиками и ресурсами, в Ливане сохраняется ряд проблем. В частности, это проблемы, связанные с ограничениями страхового покрытия психических расстройств, отсутствием
\end{abstract}


обучения работников в усло-виях междисциплинарных команд в амбулаторном звене и нежеланием некоторых врачей осваивать новые методы работы. Для развития в Ливане системы помощи по месту житель-ства необходимо увеличение численности персонала, знакомого с научно обоснованными методами и работающего в пациент-центрированном подходе в минимально ограничиваю-щих пациента условиях. Содействовать этому должен закон о психиатрической помощи, необходимость в разработке и принятии которого давно назрела.

Keywords: community mental health, psychiatric services, Eastern Mediterranean, Lebanon, global mental health Ключевые слова: амбулаторная психиатрическая помощь, психиатрическая служба, Восточное Средиземноморье, Ливан, глобальное психическое здоровье

\section{INTRODUCTION}

Lebanon, located within the WHO-defined Eastern Mediterranean region, is an upper middle-income country of more than 5.5 million people. Mental and substance use disorders are among the leading causes of the health burden in Lebanon, with an estimated rate of disability-adjusted life years amounting to 1872 per 100,000 population [1] and a suicide mortality rate of 3.3 per 100,000 population [2]. It has been estimated that approximately one in four people in Lebanon suffers from at least one mental disorder [2]. War traumas, civil conflicts and overall political turmoil have historically contributed to high prevalence rates of mental illness in Lebanon [2-4]. With ongoing national and regional economic and political instability, such estimates are likely to continue increasing in the foreseeable future. Furthermore, the ongoing conflict in neighbouring Syria poses added challenges to mental health service access within the refugee population, which has increased population numbers by around 30\% [5]. Surprisingly, only a fifth of people in Lebanon with mental disorders have sought medical care, and the vast majority cite low perceived need for treatment as a barrier [6]. Prolonged delays in seeking adequate mental health $(\mathrm{MH})$ care among people in Lebanon have also been described [7]. As will be discussed in detail later, Lebanon's mental health service delivery model is mostly that of an overarching private sector, offering centralized hospital-based care to those who perceive the need for and can afford the expense of mental healthcare.

With an escalating national burden of mental and substance use disorders, along with a slowly increasing awareness of psychiatric illnesses but an unmatched service supply, it is high time to examine the role of community-based mental healthcare $(\mathrm{CBMH})$ in the context of Lebanon. The aim of this review is to describe the significance of introducing or expanding $\mathrm{CBMH}$ in Lebanon while exploring the local and national opportunities and challenges of such an undertaking.

\section{BRIEF HISTORICAL PERSPECTIVE}

The history of specialist psychiatric hospitalization is relatively recent in Lebanon, with the opening of the Lebanon Hospital for the Insane at Asfouriyeh in August 1900, under British leadership. This hospital closed its doors in 1983 due to a combination of political and financial circumstances. In the early twentieth century, French missionaries established another mental hospital, the Hospital of the Cross (Deir El Saleeb), miles north of the capital, Beirut. In 1959, shortly after its establishment, Dar Al-Ajaza Al-Islamiya (the Islamic Nursing Home) inaugurated a division for mental healthcare, mostly in the form of chronic residential care [8]. All institutions delivered asylum-based care that was in line with the standards of the time and appropriate for the perceived needs of society. Yet, the stigmatization surrounding psychiatric hospitalization meant that Asfourieh and Deir El Saleeb became associated with horror and desolation in the popular imagination. In fact, aside from opening the substance detoxification unit at Dahr El Bachek Hospital (2014) and the inpatient unit at Rafik El Hariri Hospital (2018) during the last ten years, the government has made no attempt to develop the state sector, preferring instead to subsidize inpatient beds in private hospitals [9]. This has meant that for decades, care provision was outsourced without oversight and potential reform of the mental health sector all but stalled. 


\section{OVERVIEW OF THE LEBANESE MENTAL HEALTH SYSTEM}

Mental health systems in Lebanon are governed by a decree law (ACT\#72) enacted in 1983, which specifies the organizational structure of $\mathrm{MH}$ services, along with measures to protect and regulate human rights, guardianship issues and access to in-hospital care for the most vulnerable groups [10]. Another law (ACT\#673) pertains to substance use and focuses on supply reduction, penal provisions and drug control, while classifying substance use as a crime with sanctions.

The Lebanese $\mathrm{MH}$ system is fragmented, with most $\mathrm{MH}$ services being provided through the private sector with specialized outpatient and inpatient care. At the present time, mental health is poorly integrated with primary healthcare centres or dispensaries [11]. Dedicated outpatient mental health services mostly comprise private clinics for psychiatric or psychological care, either in independent practices or within academic hospitals. Lebanon has eight psychiatric wards (all units within general hospitals), which equates to 1.5 psychiatric beds per 100,000 population and five active mental hospitals (28.52 beds/100,000 population). Among the mental hospitals, Deir El Saleeb is the largest, offering 1000 psychiatric beds [12], followed by Dar El Ajaza, offering 377 psychiatric beds [8]. Of note, among those discharged from mental hospitals, less than $25 \%$ have been found to access follow-up outpatient care within one month of discharge.

Apart from distribution of $\mathrm{MH}$ services by sector, the $\mathrm{MH}$ workforce is generally limited in Lebanon. With a total of 1346 governmental and non-governmental $\mathrm{MH}$ professionals nationally, there are only $23 \mathrm{MH}$ workers per 100,000 population in Lebanon (compared to a median of $70 \mathrm{MH}$ workers/100,000 population in highincome World Bank countries). For every 100,000 persons in Lebanon, there are 1.21 psychiatrists, 3.14 nurses and 3.3 psychologists. Despite these shortcomings, Lebanon has made great progress in improving mental health resources compared to the rest of the Arab world. In fact, Lebanon made the most significant improvement between 1998 and 2007 in terms of increasing the availability of psychiatric beds, psychiatrists, psychiatric nurses and social workers [13].

In 2017, Lebanon spent 5171.24 LBP/capita (equivalent to $3.43 \mathrm{USD/capita)}$ on mental health (compared to 21.7 USD and 11.8 USD per capita in the WHO European and
Americas regions, respectively). Moreover, Lebanese $\mathrm{MH}$ services are poorly and disparately financed, with persons paying at least $20 \%$ towards the cost of $\mathrm{MH}$ services or psychotropic drugs. In fact, a third of the population in Lebanon is not health-covered (excluding Syrians and Palestinians living in camps who are covered by different United Nations agencies). Only 5\% of total governmental health expenditure is allocated to mental health services ( $50 \%$ of which is allocated to inpatient care). Moreover, within the private sector, almost all private insurance and mutual funds do not cover MH services.

\section{THE URGENT NEED FOR COMMUNITY SERVICES}

Perhaps the most pressing need for $\mathrm{CBMH}$ in Lebanon stems from the obvious imbalance between supply and demand for mental health services. To add to this, the lack of a regulated national healthcare referral system implies that people seeking mental healthcare, more often than not, bypass primary healthcare services, accessing professional mental health clinics directly. Given the prevalence of mental illness in Lebanon, along with the paucity of a specialized mental health workforce, the existing specialized $\mathrm{MH}$ care model is headed towards burnout.

Currently, MH services are concentrated in the capital, Beirut, or to a limited extent, within large academic institutions across the country. The obvious implication of this is a lack of conveniently accessible MH services for communities at a distance from the capital. It is not uncommon for $\mathrm{MH}$ professionals in Beirut to treat patients who have travelled over 30 miles to access quality care. Apart from the direct burden of such travel, this health-seeking behaviour in the long run is bound to increase the risk of caregiver burnout, non-compliance and possibly a deterioration of the clinical condition.

$\mathrm{MH}$ care in Lebanon is expensive, understandably so as it is usually offered by specialized $\mathrm{MH}$ professionals owing to the inadequate and/or insufficient integration of mental health within the primary care model. With psychotropic drugs not covered fully by healthcare plans (governmental or private), this further exacerbates the financial burden of mental illness on patients and those involved in their care.

Stigma towards mental illness remains a barrier to care in Lebanon and the Eastern Mediterranean Region generally. As such, many of the severely ill patients 
(or their families) shy away from $\mathrm{MH}$ care services to avoid being labelled "crazy". Alternatively, lack of MH awareness (about the existence of mental illness or the availability of scientific treatments) might lead many to seek treatment through spiritual or religious healers. Unfortunately, mainstream local media tends to be sensational more than informative, thereby conveying extreme views on the nature of and evidence-based treatment for mental disorders.

Currently, any patient in Lebanon who presents at an emergency department, and who warrants close psychiatric follow-up, will be recommended for inpatient admission, simply due to the lack of a follow-up system to bridge inpatient and outpatient care. As a result, and in light of the difficult $\mathrm{MH}$ financing situation, most of these patients will be discharged from the ED against medical advice [14]. Partial hospitalization or intensive outpatient programmes therefore have a critical role to play in closing this significant gap in mental healthcare.

\section{EXISTING COMMUNITY MH SERVICES}

Specialist care programmes for $\mathrm{MH}$ disorders have been set up in many countries, including Europe, Australia and, more recently, in the United States. These programmes usually offer early assessment services, inpatient and outpatient accommodation, and day treatment visits. They encompass a team of psychiatrists, psychologists, nurses and case managers to ensure appropriate and continuous patient care. Studies have shown that patients in specialist care programmes have fewer hospital admissions, diminished negative symptoms and a better quality of life, compared to those receiving standard care. Additionally, these programmes have been found to have positive effects on relapse and readmission rates among patients, and improved social and occupational functioning [15].

In Lebanon, psychotic disorders, including schizophrenia and related conditions, are the most prevalent in psychiatric hospitals. However, deficits still exist in the treatment of these patients. There is minimal interaction between primary care and $\mathrm{MH}$ sectors in this country, and primary care staff are not trained at recognizing or providing support for this patient population. It is thus essential that new MH services are established which aim to reduce delays in treatment, educate families about psychosis, reduce admission rates and finally put in place long-term plans to maintain progress.
The only specialist programme targeting patients with severe mental disorders is the Psychosis Recovery Outreach Program (PROP), established at the American University of Beirut Medical Center (AUBMC) in February 2016 [16]. Its primary goal is to adapt evidenced-based models of care to the Lebanese setting. Affordability for patients is an essential parameter since private or public reimbursement for psychiatric services is limited. Additionally, patients enrolled in the programme are provided with a once-a-week drop-in visit, free of charge, with home nursing visit services, which became available as of May 2017. The programme includes individual supervision sessions as well as weekly group meetings where patient updates are discussed. Professionals (psychiatrists, psychologists and nurses) acquire understanding of the various roles of their colleagues to ensure shared ownership of the caseload. Referral numbers are increasing due to public awareness campaigns and information dissemination. To date, almost 70 patients have benefited from PROP services; these patients initially presented with challenging conditions and may well have been hospitalized without this programme. The PROP offers flexibility for patients and clinicians and an opportunity to create a research database for this clinical population.

Another more recently established programme is the partial hospitalization programme (PHP), also at the American University of Beirut Medical Center. This programme functions as a bridge between full inpatient admission and community treatment. It primarily targets patients with severe mood disorders and complex presentations who require intensive intervention to mitigate risk and enable a strong therapeutic relationship to be maintained. The daily programme operates between 8 a.m. and 3 p.m. on weekdays and is delivered mostly in a group format, coupled with individual therapy and frequent psychiatric reviews. Although it has only been running since February 2019, it has been well received by patients and caregivers and has led to a reduction in the length of inpatient admissions (avoiding them altogether in some cases).

Community health services are growing along with increased public awareness in Lebanon and efforts to reduce social stigma. However, resources such as financial support and availability of professionals are still very limited. 


\section{OPPORTUNITIES FOR DEVELOPMENT}

The deficit in demand-commensurate $\mathrm{CBMH}$ services in Lebanon does not mean that the country and culture are not, in fact, equipped to establish such models of $\mathrm{MH}$ care.

The brain drain continues to prevail throughout predominantly educated sections of society, with most graduating physicians seeking training opportunities in the West. A significant proportion of these physicians do return to establish their careers in Lebanon upon completion of clinical training abroad. As such, practising psychiatrists in Lebanon who have followed this training route have already been exposed to and are equipped to establish large-scale CBMH services across the nation, provided funding is made available. With the MOPH's 2015-2020 MH strategy (in line with the WHO's MH GAP programme), the scaling up of $\mathrm{MH}$ services (including financing and PHC integration) is being given national priority, in the hope that this translates into creation and expansion of CBMH services.

The tight-knit nuclear family structure prevalent across Lebanon plays an important role in welcoming the idea of and helping to implement $\mathrm{CMBH}$ models nationally. Most patients with moderate to severe mental illness are cared for by nuclear family members who offer support across multiple domains: psychological, financial, vocational and housing. Although the CBMH model is not formally applied, specialized outpatient and inpatient $\mathrm{MH}$ care has informally touched upon many aspects of $\mathrm{CBMH}$. Most patients with moderate-severe illness present at $\mathrm{MH}$ clinics or inpatient wards accompanied by family members. Family meetings for psychoeducation and collective treatment-plan development are customary in most inpatient units within general hospitals and are generally appreciated by both patients and families alike.

\section{ANTICIPATED CHALLENGES ASSOCIATED WITH IMPLEMENTING CBMH IN LEBANON AND SUGGESTIONS FOR OVERCOMING THESE}

The most significant barrier to achieving quality $\mathrm{CBMH}$ across Lebanon, and across most LMICs, is the lack of funding $[17,18]$. Apart from the MOPH's relatively recent commitment to broadening and standardizing $\mathrm{MH}$ services generally, the financing of $\mathrm{CBMH}$ specifically remains a challenge. As such, efforts must be made to seek funding from UN agencies or WHO members who are well aware of the efficiency and efficacy of CBMH models.
Transgenerational stigma associated with mental illness needs to be addressed so that people will be more inclined to seek access to $\mathrm{MH}$ care when this is indicated [17]. CBMH models are most efficient when catering for large numbers, and as such, media and NGOs play a crucial role in responsibly disseminating evidencebased information on mental illness to communities on a large scale.

Research into psychotic disorders, for example, is still embryonic in Lebanon, with only a handful of publications (not yet a double-digit figure). This includes epidemiological and intervention-based studies. Local funding opportunities are unlikely to cover significant research in this field. Researchers rely on international grants targeting low- and middle-income countries (LMIC). These are rarely specific to $\mathrm{MH}$ and are highly competitive. Establishing reliable clinical databases that can be used for future research is easier in a multidisciplinary community-based model. With the existing presence of knowledge translation and policy information tools, data gathered from such mental healthcare processes can then be used to generate more specific MH targeted national policies [19].

It has also been noticed that non-governmental organizations and $\mathrm{MH}$ advocates put less emphasis on schizophrenia and related disorders compared to disorders that are considered "less severe". It has been hypothesized that this is due to a public that connects more with common causes such as anxiety, depression and suicidality. The public health burden of severe mental disorders remains understudied and underreported.

The $\mathrm{MH}$ workforce deficit might pose a challenge when it comes to establishing $\mathrm{CBMH}$. As such, medical doctors, registered nurses and social workers must be given sufficient incentive to specialize in psychiatric care. In the absence of a funded nationwide public initiative to shift care from hospitals to the community, the incentive for developing $\mathrm{CBMH}$ in a health economy driven by private practice has to combine affordability for the patient with a sustainable business model for the clinician. This effort relies primarily on convincing psychiatrists, who are currently often the exclusive providers of care, of the benefits of the CBMH model while guaranteeing them a pivotal role within it. The $\mathrm{MH}$ needs of the nation will continue to grow over the coming years in parallel to the increase in population but also due to increased awareness of the importance 
of mental health and the need to address it. There is no indication that the number of psychiatrists graduating each year can fill the gap between need and demand without a radical shift in practice. Unfortunately, given the dearth of local training opportunities in $\mathrm{CBMH}$, upand-coming psychiatrists are bound to replicate modes of practice within their comfort zone. They will still rely on the clinic-inpatient dichotomy that has proven its inadequacy for a number of psychiatric disorders.

Moving towards a community-based $\mathrm{MH}$ paradigm can translate into better care, provided at a more affordable cost for the end user and the provider. It also provides opportunities for development of new roles and positions for $\mathrm{MH}$ professionals from a variety of disciplines, as has happened globally. MH nursing is the branch to benefit the most as it will no longer be limited to acute inpatient settings. Nurses equipped with relevant skills for the assessment and management of psychiatric conditions can form the backbone of $\mathrm{CBMH}$, enabling psychiatrists to widen their caseload without compromising the quality or frequency of clinical contact. Nurses are now seeking higher-level training and better opportunities for pay and professional reward. If these are not provided soon in Lebanon, we will run the risk of losing out to the GCC countries, Europe or beyond. Other professionals are also required for full implementation of community services. These include social workers trained in addressing mental health, occupational therapists and also various levels of support workers. The field of clinical psychology is undergoing reform as licensing has come into force over the last few years. While there is still much work to be done to ensure the quality of psychological care, this is a positive step forward. Psychologists are now expected to demonstrate adequate supervision before establishing themselves in independent practice. This is an opportunity for them to come into contact with a wider variety of patients and with evidence-based interventions being applied in academic institutions. In parallel, universities and postgraduate training programmes should be encouraged to incorporate community $\mathrm{MH}$ into their curriculum or provide specialist modules for those interested in pursuing a career in the field. Ultimately, we aim to achieve $\mathrm{CBMH}$ models tailored to different communities with differing psychiatric needs. More effort needs to be dedicated to community services for children and adolescents, LGBT communities, substance users and patients with neurocognitive impairments, among others. Such an undertaking requires close collaboration with existing outpatient services and NGOs serving as a link to the relevant communities. For instance, the iCAN programme (intensive Child and Adolescent Neuropsychiatric Disorders Treatment Program) at the AUBMC already offers intensive outpatient services for children and adolescents with mood and anxiety disorders [20]. The Agnes Varis Healing Program for Substance Use Disorders at the AUBMC is another outpatient model of care for individuals struggling with substance use [21].

Finally, any successful community intervention needs to take into consideration the local geographical and logistical conditions while building on the experience of more developed nations [22]. Although Lebanon is a small country, it is densely populated and is lacking in terms of the availability of public transportation. Access to services outside the capital, Beirut, has been a prominent issue for many patients. CBMH could easily be established in the four or five population centres outside Beirut, to provide care for the surrounding areas. Sidon, Tyre, Tripoli and Zahle have the resources and workforce to house such services initially while $\mathrm{CBMH}$ expands nationwide and becomes the primary method of care delivery for the majority of patients with mental health conditions.

Author Contributions: All authors were equally involved in the literature review, manuscript write-up and review.

Funding: The authors declare that there was no funding for this work.

Conflict of Interest: The authors declare no conflict of interest.

Correspondence to:

Raghid Charara

rc37@aub.edu.lb

\section{References}

1. Global Burden of Disease Collaborative Network. Global Burden of Disease Study 2017 (GBD 2017) Results. Available at http:// ghdx.healthdata.org/gbd-results-tool

2. Karam EG, Mneimneh ZN, Karam AN, Fayyad JA, Nasser SC, Chatterji S, Kessler RC. Prevalence and treatment of mental disorders in Lebanon: a national epidemiological survey. Lancet. 2006 Mar 25;367(9515):1000-6. doi: 10.1016/S01406736(06)68427-4. PMID: 16564362; PMCID: PMC2030488. 
3. Chahine LM, Chemali Z. Mental health care in Lebanon: policy, plans and programmes. East Mediterr Health J. 2009 NovDec;15(6):1596-612. PMID: 20218153.

4. Farhood LF, Dimassi H. Prevalence and predictors for posttraumatic stress disorder, depression and general health in a population from six villages in South Lebanon. Soc Psychiatry Psychiatr Epidemiol. 2012 Apr;47(4):639-49. doi: 10.1007/s00127011-0368-6. Epub 2011 Apr 1. PMID: 21455787.

5. El Chammay R, Ammar W. Syrian crisis and mental health system reform in Lebanon. Lancet. 2014 Aug 9;384(9942):494. doi: 10.1016/S0140-6736(14)61329-5. PMID: 25110270.

6. Karam EG, Karam GE, Farhat C, Itani L, Fayyad J, Karam AN, Mneimneh Z, Kessler R, Thornicroft G. Determinants of treatment of mental disorders in Lebanon: barriers to treatment and changing patterns of service use. Epidemiol Psychiatr Sci. 2019 Dec;28(6):655-661. doi: 10.1017/S2045796018000422. Epub 2018 Aug 13. PMID: $30101735 ;$ PMCID: PMC6998990.

7. Karam EG, Mneimneh ZN, Dimassi H, Fayyad JA, Karam AN, Nasser SC, Chatterji S, Kessler RC. Lifetime prevalence of mental disorders in Lebanon: first onset, treatment, and exposure to war. PLoS Med. 2008 Apr 1;5(4):e61. doi: 10.1371/journal. pmed.0050061. PMID: 18384228; PMCID: PMC2276523.

8. Dar Al Ajaza Al Islamia Hospital (DAIH) [Internet]. Beirut: Dar Al Ajaza Al Islamia Hospital; c2020. About the Association; [cited 2007 Mar 28]. Available from https://daih.org/portal/ en-US/about-us/7/

9. Katchadourian $\mathrm{H}$. The historical background of psychiatry in Lebanon. Bull Hist Med. 1980 Winter;54(4):544-53. PMID: 7004545.

10. Republic of Lebanon Ministry of Public Health [Internet]. Beirut: Ministry of Public Health. Mental Health and Substance Use Prevention, Promotion, and Treatment - Situation Analysis and Strategy for Lebanon 2015-2020 Version 1.1.; Oct 2017 [cited 2020 June 15]. Available at https://www.moph.gov.lb/userfiles/ files/Mental\%20Health\%20and\%20Substance\%20Use $\% 20$ Strategy\%20for\%20Lebanon\%202015-2020-V1_1-English.pdf

11. American University of Beirut [Internet]. Beirut: Knowledge to Policy (K2P) Center. El-Jardali F, Yehia F. K2P Policy Brief: securing access to quality mental health services in primary health care in Lebanon; 2014 [cited 2020 June 15]. Available from https:// www.aub.edu.lb/k2p/Documents/K2P\%20Policy\%20Brief\%20 Mental\%20Heath.pdf

12. Republic of Lebanon Ministry of Public Health [Internet]. Beirut: Ministry of Public Health. Psychiatric Hospital of the Cross; [cited 2020 Aug 15]. Available from https://moph.gov.lb/en/ HealthFacilities/view/3/188/74130/psychiatric-hospital-of-thecross/?facility_type $=8$
13. Okasha A, Karam E, Okasha T. Mental health services in the Arab world. World Psychiatry. 2012 Feb;11(1):52-4. doi: 10.1016/j. wpsyc.2012.01.008. PMID: 22295010; PMCID: PMC3266748.

14. Faris N, Baroud E, Al Hariri M, Bachir R, El-Khoury J, Batley NJ. Characteristics and dispositional determinants of psychiatric emergencies in a University Hospital in Beirut. Asian J Psychiatr. 2019 Apr;42:42-47. doi: 10.1016/j.ajp.2019.03.024. Epub 2019 Mar 26. PMID: 30951932.

15. McGorry PD, Edwards J, Mihalopoulos C, Harrigan SM, Jackson HJ. EPPIC: an evolving system of early detection and optimal management. Schizophr Bull. 1996;22(2):305-26. doi: 10.1093/ schbul/22.2.305. PMID: 8782288.

16. El-Khoury J, Ghazzaoui R, Ahmad A. Introducing Specialist Integrated Mental Health Care in Lebanon: The Psychosis Recovery Outreach Program. Psychiatr Serv. 2018 Jul 1;69(7):738740. doi: 10.1176/appi.ps.201800018. Epub 2018 Mar 15. PMID: 29540116.

17. Khoury B, Daouk S. Community Mental Health and Mental Health Promotion-Lebanon. In: Global Mental Health: Prevention and Promotion. Cham, Switzerland: Springer International Publishing; 2017; 193-206. doi: 10.1007/978-3-319-59123-0.

18. McDaid D. Financing Mental Health in Low- and Middle-Income Countries: Making an Economic Case to Support Investment. In: Mental Health Economics: The Costs and Benefits of Psychiatric Care. Cham, Switzerland: Springer International Publishing; 2017; 193-204. doi: 10.1007/978-3-319-55266-8.

19. Yehia F, El Jardali F. Applying knowledge translation tools to inform policy: the case of mental health in Lebanon. Health Res Policy Syst. 2015 Jun 6;13:29. doi: 10.1186/s12961-015-0018-7. PMID: 26047619; PMCID: PMC4461900.

20. American University of Beirut Medical Center [Internet]. Beirut: American University of Beirut Child and Adolescent Psychiatry Division and Services. Intensive Child and Adolescent Neuropsychiatric Disorders Treatment Program (iCAN) [cited 2020 Mar 26]. Available from http://www.aubmc.org/clinical/ Psychiatry/Pages/main/Child-Adolescent-Psychiatry-DivisionServices.aspx

21. American University of Beirut Medical Center [Internet]. Beirut: American University of Beirut. The Dr Agnes Vares Healing Program for Substance Use Disorders [cited 2020 Apr 26]. Available from http://www.aubmc.org/patientcare/spe_cli_pro_ser/Pages/ Agnes-Varis-Healing-Program-Substance-Use-Disorders.aspx

22. Thornicroft G, Alem A, Antunes Dos Santos R, Barley E, Drake RE, et al. WPA guidance on steps, obstacles and mistakes to avoid in the implementation of community mental health care. World Psychiatry. 2010 Jun;9(2):67-77. doi: 10.1002/j.2051-5545.2010. tb00276.x. PMID: 20671888; PMCID: PMC2911080. 